\title{
Assessing the Role of Government in Promoting Small Scale Businesses in Kogi State: The Kabba/Bunu Experience
}

\author{
${ }^{1}$ Adeusi, S.O. (Ph.D), ${ }^{2}$ Aluko, O.A \\ ${ }^{I}$ Department of Banking and Finance Ekiti State University, Ado Ekiti \\ ${ }^{2}$ Department of Banking and Finance Ekiti State University, Ado Ekiti
}

\begin{abstract}
This study assesses the role of government in promoting small scale businesses in Kogi State, Nigeria with special focus on Kabba/Bunu Local Government Area. Questionnaires were distributed among forty (40) small scale business owners randomly selected. Regression analysis and analysis of variance (ANOVA) method were employed in the study. The results show that there is a positive correlation between government role and small scale business promotion and government play a significant role on small scale businesses in Nigeria through their various actions. The study recommends among others that government should compel banks to set aside certain percentage of their credit distribution for lending to small businesses and always consider the size of the business and profit generated when levying tax on them.
\end{abstract}

Keywords: Small Scale Businesses, Government, Promotion, Regression Analysis, Analysis of Variance, Kabba/Bunu. Kogi State

\section{Introduction}

The emergence of small scale businesses (SSBs) is tantamount to the emergence of entrepreneurs. Small business owners are regarded as entrepreneurs. Small businesses are used to foster entrepreneurship. This would make the nation to be self-reliant, economically viable and socially balanced, and there will be jobs for so many people. They are identified as instruments for improving standard of living in a country.

For a developing country like Nigeria to reduce the alarming rate of poverty, Nigerians irrespective of their status, educational attainment, religion, gender etc, must embrace entrepreneurship i.e. owning a business. SSBs account for more than 50\% of the total share of employment, sales and value added (Udechukwu, 2003). The development of SSBs by the government is a move in the direction to increase economic growth. Ekpeyong and Nyong (1992) suggested that SSBs are organic part of a viable structure for sustainable economic development in less developed countries like Nigeria. They have the tendency to produce greater benefits for the economy than large enterprises because they have higher multiplier effects.

Ojo (2009) put forth one of the solutions to the problems of development in Nigeria is the promotion of entrepreneurial development scheme. A veritable way to do this is government promotion of small scale businesses. Entrepreneurship has been identified as vital for the continued vitality of the modern market for more businesses to emerge; hence, competition and economic growth are improved (Klapper \& Love, 2011).

Efforts have been taken by the Nigerian government for the development of small scale businesses over the years. The realisation of the Millennium Development Goals (MDGs) and the vision of the Nigerian Government to be rated among the top 20 economies in the world is considerably determined by how government has recognised SSBs as drivers of economic growth and key strategy for poverty alleviation. However, the over-reliance on natural resources especially crude oil as the mainstay of the economy is capable of making the attainment of their desires an illusion. Government, through its actions may be a hindrance or promoter of small scale businesses; thus, this study seeks to assess the role of government in promoting small scale businesses in Nigeria, taking the experience of small scale business owners operating in Kabba/Bunu Local Government Area in Kogi State.

The impetus for this study is driven by the notion that small scale businesses have not been given proper attention from the government to contribute meaningfully to the economy. The scope of the study is restricted to Kabba/Bunu Local Government Area in Kogi State. The rest of this study is sectioned as follows: section 2 focuses on literature review, section 3 addresses the research method, section 4 provides the empirical findings and section 5 gives the conclusion.

\subsection{Conceptual Issues}

\section{Literature Review}

There is still no generally accepted definition for small scale business. Small scale business is a type of business which individual(s) owns and manages the enterprise. It comes in form of sole proprietorship and in some cases partnership i.e. owned by two or more individuals. According to Mawoli and Aliyu (2010), small- 
scale enterprises refer to all profit-making undertakings that are small in size, have small number of employees, capital employed, number of customers and sales turnover.

Small scale business is an autonomously operated enterprise, not dominant in its area of business and meets certain criteria in terms of number of employment and annual receipts (Nickel, Mchugh \& Mchugh, 1997). Small scale business is a commercial entity with a labour force of 11-100 workers or a total cost not exceeding N 50 million, with the inclusion of working capital and exemption of cost of land. The Committee for Economic Development Standard identifies a business as small if the management is independent, capital is supplied and ownership is held by an individual or small group of people, the horizon of operation is mainly local, and considered small when compared to the biggest unit in its field of operation.

\subsubsection{Merits of Establishing Small Scale Business}

An individual that decides to go into small scale business undertakes the business with a measure of risk and perceived benefits in participating in a business venture. Small scale business owners enjoy the following advantages:

i. Profit: The owner appropriates all the profits of the business alone. He is in full control of the business because he is the owner and manager; hence, the success of the business depends on his personal efforts towards making the business flourish.

ii. Privacy: The owner is not liable to anyone for failing to disclose his business strategies. He is not bound by any existing laws to publish his account for public consumption.

iii. Direct contact with Employees and Customers: The owner has face to face contact with his employees and customers. He maintains close relations with his employees and therefore supervises them effectively to maximise output and increase efficiency. He can better also assess the credit worthiness of his customers and therefore is able to avoid incidence of bad debts and can easily attend to customers' complains in the interest of his business.

iv. Capital Requirements: The capital need for establishing small businesses is relatively small in comparison to other business firms. The owner may be able to raise capital through his personal savings, borrowing from friends and relatives, and cooperative societies etc.

v. Ease of Formation: The process of establishing a small business is not as burdensome as other firms on a large scale. The only legal document for starting this type of business is registration; a license will be issued to the owner.

vi. Quick Decision Making: The owner does not need to make consultation to anybody before taking decisions. He stands a better chance than other business forms of making quick decision.

vii. Independence: The owner is independent of anybody. As the owner, he has the privilege of being the administrative head. He bears the responsibility for his own actions.

viii. Tax Advantage: The owner pays personal income tax on the amount of income he is able to declare. It is possible for them to avoid and evade taxes. This is because they are too many and do not publish their account.

ix. Easy Dissolution: As easy as it is to start up a small scale business, so also is the ease to stop the business. The owner can dissolve the business without prior arrangement.

x. Self Interest: The interest of the owner is paramount in any business. The small scale business owner in his own interest takes every opportunity and incentives to make the business; thus, takes adequate precautions and measure to avoid wastage.

\subsubsection{Demerits of Establishing Small Scale Business}

Despite the benefits accruable from owning small scale business, there are some disadvantages which are likely to be encountered by small scale business owners. These include:

i. Lack of Finance: Small scale business owners at times find it difficult to expand their business or exploit new opportunities due to insufficient funds. The amount the owner has is limited to personal savings, borrowing from friends and relations etc. Small business owners normally do not have access to large amount of capital because of size and method of keeping accounts. Banks and other financial institutions consider them very risky borrowers and are reluctant to make loans available.

ii. Limited Scope of Expansion: Small business owners find it difficult to expand their business and reach other areas aside where the business is established.

iii. Unlimited Financial Liability: The owner's position in relation to liability for debt of the business is an unfavourable one. This is because creditors have recourse not only to the assets of the business for the settlement of their claims but also on the personal property of the owner.

iv. Lack of continuity: Small scale businesses have uncertain life span. Death, disability, theft, illness, bankruptcy, and imprisonment among others can put the operation of the business to a permanent halt. 


\subsubsection{Roles of Small Scale Business in the Economy}

According to Shokan (1997), some of the roles small scale businesses play in the economy include:

i. SSBs help in the generation of employment. In most emerging economies, SSBs account for a large proportion of firms and a large share of the employment (Safiriyu \& Njogo, 2012).

ii. SSBs bring about new goods and services and supply the needs of large enterprises, which have to depend on small scale businesses for their own success.

iii. They encourage the development of local manpower as well as increasing indigenous participation in the manufacturing sector.

iv. Rural-urban migration is abridged through the creation of SSBs in rural areas. They check the effect of divergence by a premeditated and orderly development of rural areas.

v. SSBs aid the mobilization of resources in their area of operation; thereby, increasing the living standard of the population.

\subsubsection{Sources of Finance for Small Scale Businesses}

Finance has been identified in many business surveys as one of the most important factors determining the growth of small businesses in Nigeria. The accessibility to finance allows them to engage in productive activities in a bid to improve their business operations; thus making them more competitive. Boer, Thomas and Webster (1997) noted that small businesses are financed in many ways and may use a variety of funding sources. The source of finance apart from the owner's equity can either be formal or informal. According to Owualah (1999) and Adelaja (2002), seven major sources of finance are available to SSBs. These include:

1. Personal resources.

2. Family and friends.

3. Partners or business associates.

4. Informal financial markets comprising, individuals and group, including pool fund groups and co-operative societies.

5. Financial institutions (mainly commercial banks).

6. Specialised Funding Facilities e.g. World Bank Loan Scheme for Small and Medium Scale Enterprises (SMEs) managed by Central Bank of Nigeria (CBN) and the African Development Bank (ADB) Loan Scheme for export stimulation in the SME sector, Small and Medium Industries Equity Investment Scheme (SMIEIS) etc.

7. Specialised Financial Institutions such as the Bank of Industry (BOI), Bank of Agriculture (BOA).

\subsubsection{Problems of Small-Scale Businesses in Nigeria}

Most SSBs have failed to perform at a level that makes them contribute to the growth of the economy as a result of challenged hindering their optimum functioning. Some of the challenges faced by SSBs in Nigeria include:

i. Dearth of Finance: This is a serious problem faced by small-business owners. Owners find it difficult to raise funds for investment from the financial markets (Fayomi, 2012). However, when banks decide to grant them credit, it is usually at a high interest rate (Mawoli \& Aliyu, 2010).

ii. Marketing Problem: SSBs often experience problem of marketing their goods and services. They fail to learn and employ marketing principles. Instead of making considerable sales and realising profits, they make very low sales and incurring losses.

iii. Economic Situation: According to Mawoli and Aliyu (2010), high foreign exchange rate, galloping inflations, and unstable monetary and fiscal policies pose problem for small business owners. Also, low literacy level among owners make deep understanding of the implications of certain monetary and fiscal policies very difficult especially when the policies are frequently changed.

iv. Ineptness of Managerial and Entrepreneurial Skills: Majority of small business owners in Nigeria have little or no managerial skills and often run their businesses based on luck.

v. Political Instability: Businesses irrespective of size function well under a sound political environment. Mawoli and Aliyu (2010) argued that since Nigeria gained independence, the political terrain has been highly unpredictable. They are of the opinion that there is lack of continuity with respect to economic policies; thus, long term planning becomes difficult to do.

vi. Cultural Problem: When small business owners make enough profits, rather than plough back into the business or exploit new opportunities, majority prefer to expend on unproductive activities like marrying a new wife, organising a party etc, which eventually leads to shortage of funds for them to utilise in keeping their business going.

vii. Location Problem: Some SSBs are situated in places that are remote; hence making it difficult for customers to access. Some also deal in goods and services not highly needed in location in which the business is operating. 


\subsection{Review of Related Empirical Studies}

Maunganidze (2013) focused on the role of the government on the establishment and development of small and medium enterprises (SMEs) in Zimbabwe. It identified that a great number of provisions and policies concerning these enterprises are politically motivated and are talk shows, especially when election period is near and agencies created by the government towards SMEs development are not adequately financed by the treasury. Adebisi and Gbegi (2013) examined the effect of multiple taxation on SMEs survival in Nigeria and revealed that multiple taxation has negative effect on SMEs' survival and the relationship between SMEs' size and its ability to pay taxes is significant. The study suggested that government should implement uniform tax policies that will favour the development of SMEs and put the size of SMEs as a criterion when setting tax policies.

Adejumo and Olaoye (2012) assessed the adequacy of Industrial Development Centres (IDCs) in Nigeria in funding SSBs. The study indicated that each of the selected IDCs was underfunded by the government to carry out the roles assigned to it towards the development of SSBs in the geographical areas it is established. Oni and Daniya (2012) appraised the role of government and other financial institutions particularly micro finance institutions in the development of SMEs in Nigeria. It was discovered that financial institutions provide the necessary financial assistance that enhance the development of SMEs, but, much needed to be done by the government in the area of policy formulation in order to complement the efforts of financial institutions.

Onwukwe and Ifeanacho (2011) evaluated the impact of government intervention on SME growth in Imo State, Nigeria and found that in spite of various specialised institutions in charge of micro credit and policy instruments, SMEs are being inhibited by the gap between policy and policy implementation in contributing to meaningful economic development. Hassan and Olaniran (2011) examined how assistance institutions contributed to the development of SMEs in Nigeria, with special reference to Industrial Development Centre (IDC), Osogbo. The outcome showed that the assistance institutions have enormously contributed to the promotion of SMEs and entrepreneurship development.

Mobolaji (2010) conducted a study on the impact of SMEs on economic development in Nigeria (19802008). Employing a time series econometric approach, the study found that though SME is a catalyst for development and its impact on the development path in the country is still negligible. The study suggested that the poor performance of SMEs may be due to inadequate funding facilities, low education level and poor government support amongst others. Ekot (2010) adopted the survey design focused on small business ownership and management in Uyo, Akwa Ibom State, Nigeria and identified that lack of funds and interest by the young and literate people to undertake small businesses and poor government and institutional support constitute part of the problems plaguing small businesses in Uyo metropolis and Akwa Ibom State generally.

\section{Research Method}

The primary quest of this study is to assess the role of government in promoting small scale businesses in Kogi State, taking the experience from Kabba/Bunu Local Government Area. This study employs a qualitative approach and a descriptive survey research design. Qualitative data were gathered through questionnaire structured in closed-end format.

In constructing the questionnaire, Likert-scale with a five-point options and the rating scale was adopted; thus, allowing opinions of respondents to be score their opinion on a scale of 1 to 5 . The responses on the questionnaire are restricted to Strongly Agree, Agree, Undecided, Disagree and Strongly Disagree.

\subsection{Population, Sample and Sampling Technique}

Small scale business owners operating in Kabba/Bunu Local Government Area irrespective of their demographic characteristics such as age, gender, educational qualification, marital status, religion form the population of the study. Forty (40) small scale business owners were drawn into the sample. The random sampling technique is employed in which respondents are chosen without any criteria and bias. The eligibility for selection is to be a component of the population of study.

\subsection{Research Hypotheses and Method of Analysis}

The hypotheses to be tested in this study include the following stated in nulls $\left(\mathrm{H}_{0}\right)$ :

i. Government has not taken adequate measures to promote small scale businesses.

ii. Government initiatives related to development of entrepreneurship has not enhanced the growth of small scale businesses.

iii. Government fiscal policy through taxation does not have significant impact on small scale businesses.

iv. Government policies have not encouraged financial institutions to channel funds to small scale businesses.

v. Infrastructural development by government does not foster the growth of small scale businesses. 
From the hypotheses, a linear model is built which specifies small scale businesses (SSBs) as a function of government adequate measures (GAM), government initiatives (GI), taxation (TAX), government policies on banks (GP), and infrastructural development (INF). This model is analysed using the regression analysis and ANOVA technique.

\section{Empirical Findings}

40 questionnaires were distributed and all were duly filled and returned, implying that there is $100 \%$ feedback response rate.

Table 1: Model Summary

\begin{tabular}{|l|l|l|l|l|l|}
\hline Model & $\mathbf{R}$ & R square & $\begin{array}{l}\text { Adjusted } \\
\text { square }\end{array}$ & Std error of the estimate & Durbin Watson \\
\hline 1 & 0.892 & 0.632 & 0.596 & 0.524221 & 1.82193 \\
\hline
\end{tabular}

Source: Authors' computation

Predictors: (Constant), Government Adequate Measures (GAM), Government Initiatives (GI), Taxation (TAX), Government Policies (GP) and Infrastructure Facilities (INF)

Dependent Variable: Small Scale Business (SSB)

According to the model summary in Table 1, the coefficient of determination or correlation coefficient (r) gives a high positive value of 0.892 , indicating that there is positive association between government and small scale business. This implies that as government continue to play its role, small scale businesses grow. The coefficient of multiple determination $\left(\mathrm{R}^{2}\right)$ is 0.632 ; this implies that there is a fairly strong linear relationship between the role of government and the promotion of small scale business. It can be implied that government accounts for approximately $63 \%$ of variations in the growth of small scale business operations while the remaining $37 \%$ is accounted for by factors not specified in the model i.e. error/stochastic term.

Table 2: Analysis of Variance (ANOVA)

\begin{tabular}{|l|l|l|l|l|c|}
\hline Model & Sum of Squares & dof & Mean Square & F & Sig. \\
\hline Regression & 15.114 & 9 & 2.723 & 3.218 & 0.097 \\
\hline Residual & 46.886 & 32 & 0.948 & & \\
\hline Total & 62.000 & 35 & & & \\
\hline
\end{tabular}

Source: Authors' computation

ANOVA is used to test whether government play a significant role on small scale businesses. The F test is used to determine the significance by comparing the F-calculated with the F- tabulated. The hypothesis for the test is formulated as:

$\mathbf{H}_{\mathbf{0}}$ : Government does not play a significant role on the growth of small scale businesses.

$\mathbf{H}_{1}$ : Government plays a significant role on the growth of small scale businesses.

Decision Rule: If F-calculated > F-tabulated, accept $\mathrm{H}_{1}$ and reject $\mathrm{H}_{0}$ and if F-cal< F-tab, accept $\mathrm{H}_{0}$ and reject $\mathrm{H}_{1}$.

Table 3: Summary of F-test

\begin{tabular}{|l|l|l|l|}
\hline F-calculated & F-tabulated & $\mathbf{H}_{0}$ & $\mathbf{H}_{1}$ \\
\hline 3.218 & $\mathbf{2 . 6 8}$ & Reject & Accept \\
\hline
\end{tabular}

Source: Authors' computation

From Table 3, the F-calculated gives a value greater than the F- tabulated. Hence, $\mathrm{H}_{1}$ is accepted and $\mathrm{H}_{0}$ rejected. It is therefore affirmed that government play a significant role on the growth of small scale businesses.

Table 4: Coefficients of Regression Parameters

\begin{tabular}{|c|c|c|c|c|c|c|}
\hline \multirow{2}{*}{\multicolumn{2}{|c|}{ Model }} & \multicolumn{2}{|c|}{$\begin{array}{l}\text { Unstandardized } \\
\text { Coefficients }\end{array}$} & $\begin{array}{l}\text { Standardized } \\
\text { Coefficients }\end{array}$ & \multirow[t]{2}{*}{ T-Stat. } & \multirow[t]{2}{*}{ Sig. } \\
\hline & & $\beta$ & Std. Error & Beta & & \\
\hline & (Constant) & .102 & .140 & & .732 & .466 \\
\hline & GAM & .262 & .080 & .247 & 3.256 & $.001 *$ \\
\hline & GI & .248 & .075 & .262 & 3.310 & $.001 *$ \\
\hline & TAX & .085 & .082 & .085 & 1.035 & .302 \\
\hline & GP & .070 & .084 & .068 & .833 & .407 \\
\hline & INF & .210 & .081 & .204 & 2.608 & $.010^{*}$ \\
\hline
\end{tabular}

(*) implies significant at $5 \%$ significance level 
Source: Authors' computation

From Table 4, all the parameters have their coefficients do not exceed unity i.e. 1 and are positively related to the dependent variable. The constant coefficient gives a positive value of 0.102 implying that if all explanatory variables are held constant, the promotion rate of small scale business increases by $10.2 \%$. The coefficient of GAM gives a positive value of 0.262 , implying that a unit increase GAM results in $26.2 \%$ increase in growth of small scale businesses. The coefficient of GI is 0.248 , indicating that a unit increase in GI causes $24.8 \%$ increase in small scale businesses. The coefficient of TAX is 0.085 which indicates that an increase in the value of TAX by a unit leads to $8.5 \%$ increase in small scale businesses. Also, the coefficient of GP on financial institutions to lend to SSB gives 0.070 units and this indicates that a unit increase in the GP results to $7 \%$ rise in the small scale businesses' growth. Similarly, the coefficient of INF is 0.210 and implies that a unit increase in INF causes small scale businesses to grow by $21 \%$.

\section{Conclusion}

This study assessed the role of government in promoting small scale businesses in Kogi State, with particular inclination to Kabba/Bunu Local Government Area in Kogi State. Responses from the small scale business proprietors showed that the role government plays cannot be overlooked in the growth and survival of their businesses. This study identified that without government intervention, most small scale businesses would have gone into extinction. Measures taken by the government in time past have been seen to have a significant and positive impact on their businesses. This portends that policy actions implemented by the government towards promoting small scale businesses produce a favourable outcome on their operations. Government initiatives related to entrepreneurship development has had a significant and positive influence on the performance of small scale businesses. Small scale businesses are widely seen as a training ground for the development of entrepreneurship skills. Government has identified them and has taken initiatives to develop entrepreneurship abilities in them. These initiatives have improved the performance of small scale business operations and encouraged them to continue doing business.

Government fiscal policy towards taxation has a positive effect on small scale business. However, this effect is not significant. The positive influence taxation has on small scale business owners showed that the tax policy on small scale businesses is not detrimental to their operations and they do not encounter multiple taxation. The statistical insignificance of government fiscal policy implies that it is not a government action that determines the growth of small scale businesses. Also, small scale business owners believe government has been effective in encouraging financial institutions to lend to them due to the positive effect. This finding suggested that without the role of government on financial institutions, small scale business owners might have encountered difficulty in accessing credit facilities from financial institutions. The infrastructural facilities provided by the government have contributed to the growth of small scale businesses. This is because the result showed that infrastructural development by the government has a positive and significant effect on small scale businesses.

It is pertinent to recommend policy measures so that small businesses can continue to grow and impact on the economy. The study made the following recommendations:

i. Efforts should be made by the government to channel funds to small businesses towards their development. This can be done by compelling banks to set aside certain percentage of their credit distribution for lending to small businesses.

ii. Government should consider the ability to pay tax by small business owners when implementing tax policies on them. This can be done by taking into consideration the size of the business and profit generated.

iii. Government can also grant tax holiday to small scale businesses as this would serve as a form of incentive to them.

iv. Government should continually provide small scale businesses with the necessary infrastructural facilities to enhance the growth of their businesses.

v. Government should establish more agencies meant to grant small scale businesses credit facilities as well as financial and technical advice.

\section{References}

[1]. Adebisi, J.F. \& Gbegi, D.O. (2013). Effect of Multiple Taxation on the Performance of Small and Medium Scale Business Enterprises (A Case Study of West African Ceramics, Ajaokuta, Kogi State). Mediterranean Journal of Social Sciences, Vol. 4, No.6, 323-334

[2]. Adejumo, D.G. \& Olaoye, J.A. (2012). Funding of Small-Scale Development Agencies in Nigeria: A Case Study of Industrial Development Centres (IDCs). European Journal of Business and Management, Vol. 4, No.8, 106 -123

[3]. Boer, A., Thomas, R. \& Webster, M. (1997). Small Business Management: A Resource-Based Approach. Cassel, London 
[4]. Ekpeyong, D.B. \& Nyong, M.O. (1992). Small and Medium-Scale Enterprises in Nigeria: Their Characteristics, Problems, and Sources of Finance. African Economic Research Consortium, Nairobi

[5]. Fayomi, I.O. (2012). An Appraisal of the Small and Medium Scale Enterprises on Poverty Alleviation in Southwestern State of Osun in Nigeria, OIDA International Journal of Sustainable Development, 05:04, 97-105

[6]. Hassan, M.A. \& Olaniran, S.O. (2011). Developing Small Business Entrepreneur through Assistance Institutions: The Role of Industrial Development Centre, Osogbo, Nigeria. International Journal of Business and Management, 6(2), 213-226

[7]. Klapper, L.F. \& Love, I. (2011). Entrepreneurship and Development: The Role of Information Assymetries. The World Bank Economic Review, Vol. 25(3), 448-455

[8]. Maunganidze, F. (2013). The Role of Government in the Establishment and Development of SMEs in Zimbabwe: Virtues and Vices. Journal of Business Administration and Education, Vol. 4, No.1, 1-16

[9]. Mawoli, M.A. \& Aliyu, A.N. (2010). Entrepreneurship and Small Business Management in $21^{\text {st }}$ Century Nigeria. Aboki Publishers, Makurdi

[10]. Mobolaji, H.I. (2010). Entrepreneurship and Economic Development in Nigeria. Paper Presented at College of Management and Social Sciences Seminar, Fountain University, Osogbo

[11]. Nickel, W.H., Mchugh, J. \& Mchugh, S. (1997). Understanding Business. Irwin McGraw-Hill, Illinois

[12]. Ojo, O. (2009). Impact of Micro Finance on Entrepreneurial Development: A Case of Nigeria. Paper presented at the International Conference of Economic and Administration and Business, University of Bucharest, Romania, $14^{\text {th }}-15^{\text {th }}$ November

[13]. Oni, E.O. \& Daniya, A.A. (2012). Development of Small and Medium Scale Enterprises: The Role of Government and Other Financial Institutions. Arabian Journal of Business and Management Review, Vol. 1, No.7, 16-29

[14]. Onwukwe, V.C. \& Ifeanacho, M.I. (2011). Impact of Government Intervention on the Growth of Small and Medium Scale Enterprises in Imo State. International Journal of Research in Commerce, Economics \& Management, Vol. 1, Issue 7, 1-5

[15]. Owualah, S.I. (1999). Entrepreneurship in Small Business Firm. G-MAG Investments Limited, Ikeja

[16]. Safiriyu, A.M. \& Njogo, B.O. (2012). Impact of Small and Medium Scale Enterprises in the Generation of Employment in Lagos State. Arabian Journal of Business and Management Review, Vol. 1, No. 11, 107-141

[17]. Shokan, O. (1997). Entrepreneurship Development in Small Scale Business, Labson Resource Nigeria Limited, Lagos

[18]. Udechukwu, F.N. (2003). Survey of Small and Medium Scale Industries and their Potentials in Nigeria. Central Bank of Nigeria (CBN) Seminar on Small and Medium Scale Industry Equity Investment Scheme (SMIEIS), CBN Training Centre, Lagos 